\title{
Spreadsheets in Education (eJSiE)
}

Volume 9 | Issue 2

Article 4

7-15-2016

\section{Spreadsheet-Based Pipe Networks Analysis for Teaching and Learning Purpose}

Dejan Brkic

European Commission, dejanbrkic0611@gmail.com

Follow this and additional works at: http://epublications.bond.edu.au/ejsie

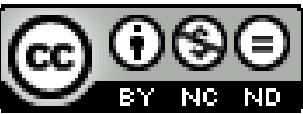

This work is licensed under a Creative Commons Attribution-Noncommercial-No Derivative Works 4.0 License.

\section{Recommended Citation}

Brkic, Dejan (2016) Spreadsheet-Based Pipe Networks Analysis for Teaching and Learning Purpose, Spreadsheets in Education (eJSiE): Vol. 9: Iss. 2, Article 4.

Available at: http://epublications.bond.edu.au/ejsie/vol9/iss2/4 


\title{
Spreadsheet-Based Pipe Networks Analysis for Teaching and Learning Purpose
}

\begin{abstract}
An example of hydraulic design project for teaching purpose is presented. Students' task is to develop a looped distribution network for water (i.e. to determinate node consumptions, disposal of pipes, and finally to calculate flow rates in the network's pipes and their optimal diameters). This can be accomplished by using the original Hardy Cross method, the improved Hardy Cross method, the node-loop method, etc. For the improved Hardy Cross method and the node-loop method, use of matrix calculation is mandatory. Because the analysis of water distribution networks is an essential component of civil engineering water resources curricula, the adequate technique better than the hand-oriented one is desired in order to increase students' understanding of this kind of engineering systems and of relevant design issues in more concise and effective way. The described use of spreadsheet solvers is more than suitable for the purpose, especially knowing that spreadsheet solvers are much more matrix friendly compared with the hand-orientated calculation. Although matrix calculation is not mandatory for the original Hardy Cross method, even in that case it is preferred for better understanding of the problem. The application of commonly available spreadsheet software (Microsoft Excel) including two real classroom tasks is presented.
\end{abstract}
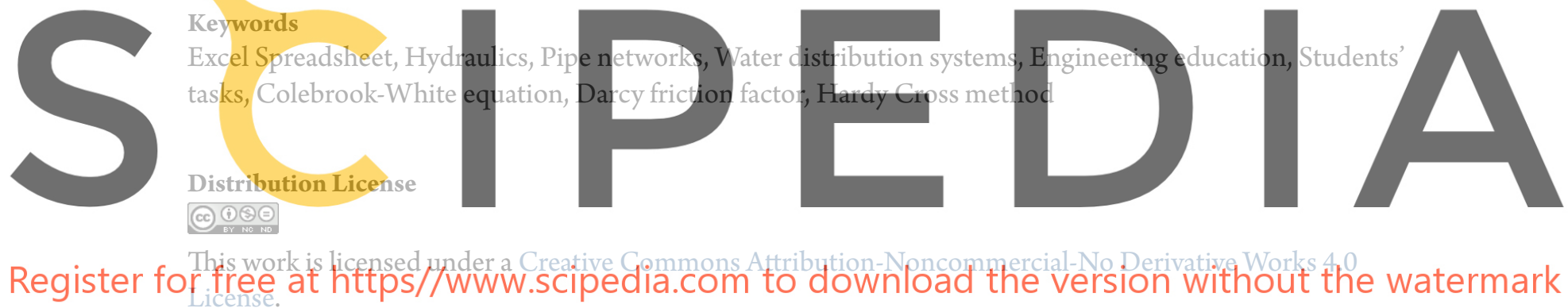

\section{Cover Page Footnote}

The views expressed are purely those of the writer and may not in any circumstance be regarded as stating an official position of the European Commission. 


\section{Spreadsheet-Based Pipe Networks Analysis for Teaching and Learning Purpose}

\section{Introduction}

In a teaching of methods for piping systems there are tensions between the study of fundamental scientific theory and the application of design methodologies. For example, students usually understand the basic idea of the well-known Hardy Cross method, but some difficulties can occur during the work on an example of design project. Only the Hardy Cross method (Cross 1936) can be used for an example project without introduction of matrix calculation. This implies that use of spreadsheet solver tools or some kind of specialised software for matrix calculation such as MATLAB are more adequate for teaching and learning of more complex methods, such as the improved Hardy Cross method and the node-loop method.

The paper will provide information about:

1. Hydraulic background; introduction of physical laws which governs flow of water through one single pipe including determination of hydraulic resistances, and laws of flow through looped networks of pipes;

2. Details about methods used for calculation of flow through looped networks of pipes including specific tasks to be assigned to students (complete

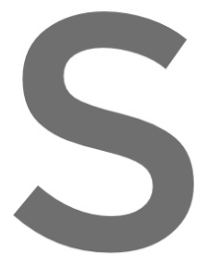
spreadsheets with

3. Information about teaching backgroun

1. Hydraulic laws used for calculation
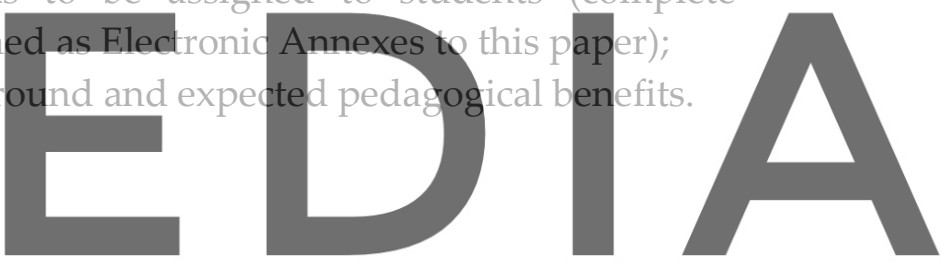

Some details about calculation of hydraulic resistances regarding flow through a single

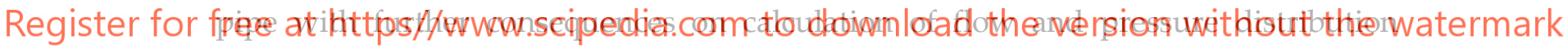
through a network of looped pipes will be provided in this Section.

\subsection{Fluid in pipes and flow}

Fluid in a network of pipes beside the water can be natural gas for distribution in the municipalities (Manojlović et al. 1994, Brkić 2009, Pambour et al. 2016), oil (Brimberg et el. 2003), air in the case of ventilation systems in buildings or mines (Aynsley 1997), etc. Turbulent flow resistance which occurs in a single pipe is usually described by the empirical Colebrook's equation (Colebrook 1939) developed from the experiment conducted by Colebrook and White (1937). The diagram which corresponds to the Colebrook's equation was developed Moody (1944) inspired by the work of Hunter Rouse (in Australia the Moody diagram is known also as the Rouse diagram). Flow resistance $\lambda$ in our case will be calculated using the Colebrook's equation (1):

$$
\frac{1}{\sqrt{\lambda}}=-2 \cdot \log _{10}\left(\frac{2.51}{\operatorname{Re} \cdot \sqrt{\lambda}}+\frac{\varepsilon}{3.71 \cdot \mathrm{D}}\right)
$$

$\lambda$-flow friction factor, known also as Darcy, Darcy-Weisbach or Moody friction factor (dimensionless);

$\varepsilon / D-$ Relative roughness of inner surface of pipe (dimensionless);

Re-Reynolds number (dimensionless) defined by (3): 


$$
\operatorname{Re}=\frac{v \cdot D}{\mu}=\frac{4 \cdot|Q|}{\pi \cdot \mu \cdot D}
$$

v-velocity of flow (m/sec);

D-inner pipe diameter $(\mathrm{m})$;

$\mu$-kinematic viscosity of fluid $\left(\mathrm{m}^{2} / \mathrm{sec}\right)$;

Q-volumetric flow rate $\left(\mathrm{m}^{3} / \mathrm{sec}\right)$; and

$\pi$-Ludolph number, $\pi \approx 3.1415$.

Because the Colebrook's equation is with unknown quantity $\lambda$ on the both sides of equal sign, i.e. $\lambda$ is given in implicit way, iterative procedure has to be followed where some additional details can be found in Brkić (2012a).

To work with iterative calculation and to allow necessary implicit calculation in Microsoft Excel, 'Office button' at the upper-left corner of the Excel screen has to be pressed, and in the 'Excel options' 'Formulas' has to be chosen where finally box 'Enable iterative calculation' has to be ticked. This allows implementation of so called 'Circular references' into a calculation. To avoid such iterative calculus, as an alternative, students involved in such computational tasks can use some of the available explicit approximations to the Colebrook's equation where their codes suitable for Microsoft Excel can be found in Brkić (2011a) and Ćojbašić and Brkić (2013).
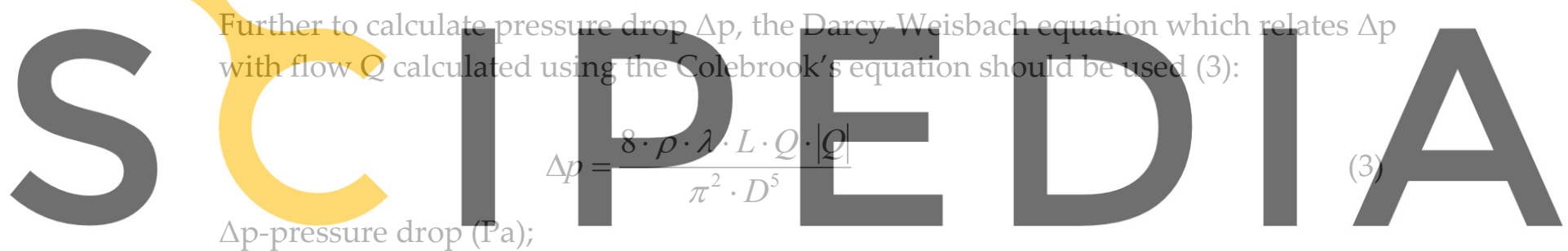

Register for free at https//www $/ \mathrm{kg}$ - $\left.\mathrm{m}^{3}\right)$; $\lambda$-flow friction factor, known also as Darcy, Darcy-weisbach or Moody friction factor

(dimensionless);

L-pipe length (m);

Q-volumetric flow rate $\left(\mathrm{m}^{3} / \mathrm{sec}\right)$;

D-inner pipe diameter $(\mathrm{m})$; and

$\pi$-Ludolph number, $\pi \approx 3.1415$.

In electrical circuits equation related to the Darcy-Weisbach's (3) is the Ohm's equation which relates voltage (pressure drop $\Delta \mathrm{p}$ is equivalent in hydraulics), electrical current (volumetric flow $\mathrm{Q}$ is equivalent in hydraulics) and electrical resistance (in common electrical circuits it is constant while in hydraulics, flow resistance depends on density of fluid, flow friction factor, pipe length and on inner pipe diameter). Also, the Ohm's law is linear with the thermal resistance almost always given with a constant value while the Darcy-Weisbach law is quadratic with hydraulic resistance changeable in relation to the flow rate (where flow friction factor $\lambda$ depends on the Reynolds number Re which further depends on flow rate Q).

Note that in addition to the Darcy, Darcy-Weisbach or Moody friction factor, in this paper noted as $\lambda$, some researcher use the Fanning friction factor which is one-fourth 
of the Darcy friction factor. The Fanning friction factor is the more commonly used by chemical engineers and those following the British imperial system of measures.

Some researchers use less reliable Hazen-Williams relation instead of the Colebrook's equation to correlate water flow, pressure drops in pipes and hydraulic frictions (Liou 1998; Travis and Mays 2007).

Possible additional tasks for students. Combining Colebrook's (1), Darcy-Weisbach's (2) and Reynolds' relation (3), flow $Q$ in a way to avoid iterative calculus has to be expressed (Swamee and Rathie 2007); Solution is given with Eq. (4):

$Q=-\frac{D^{2} \cdot \pi \cdot \sqrt{D \cdot \Delta p}}{\sqrt{2 \cdot \rho \cdot L}} \cdot \log _{10}\left(\frac{2.51 \cdot \mu \cdot \sqrt{2 \cdot \rho \cdot L}}{2 \cdot D \cdot \sqrt{D \cdot \Delta p}}+\frac{\varepsilon}{3.71 \cdot D}\right)$

Q-volumetric flow rate $\left(\mathrm{m}^{3} / \mathrm{sec}\right)$;

D-inner pipe diameter $(\mathrm{m})$;

$\Delta$ p-pressure drop $(\mathrm{Pa})$;

$\rho$-density of fluid $\left(\mathrm{kg} / \mathrm{m}^{3}\right)$;

$\mu$-kinematic viscosity of fluid $\left(\mathrm{m}^{2} / \mathrm{sec}\right)$;

L-pipe length (m);

$\varepsilon / D$-Relative roughness of inner surface of pipe (dimensionless); and

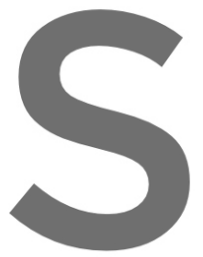

$\pi$-Ludolph number, $\pi \approx 3.1415$.
Further additional tasks for students
Colebrook's equation through the Lambert
Brkić 2011b, 2012 b, 2017; Rollmann and Sp
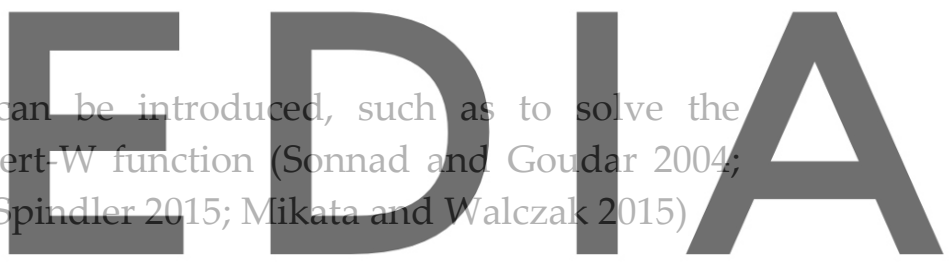

1.2. Flow through looped network of pipes

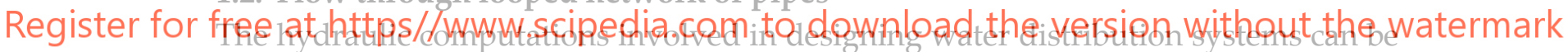

only approximated as it is impossible to consider all the factors affecting loss of head

in a complicated network of pipes. In a water distribution system, the friction head losses usually predominate where other minor losses can be ordinarily neglected without serious errors (Chansler and Rowe 1990). The calculation of friction head losses is explained in the previous Section of this paper.

The steady-state flow distribution of an incompressible fluid through a piping network is governed by mass and energy balance. Mass balance is governed by the first Kirchhoff's law while energy balance is governed through the second Kirchhoff's law. The problem is not linear such as in electric circuits and an iterative procedure must be used. The hydraulic network can be compared with the electric network when diodes are in circuit instead of common resistors. In hydraulic networks, initial flow distribution has to be randomly chosen but in that way to satisfy mass balance for every node within the network (first Kirchhoff's law). Such random distribution will not simultaneously satisfy energy balance for all loops of pipes within the network (second Kirchhoff's law) where these balance will be found using iterative procedure such as those proposed by Hardy Cross in the basic form and later improved and accelerated by many researchers (Shamir and Howard 1968; Epp and Fowler 1970; Hamam and Brameller 1971; Wood and Charles 1972; Wood and Rayes 1981; Todini and Pilati 1988). 
All methods assume equilibrium between pressure and friction forces in steady and incompressible flow. As a result, they cannot be successfully used in unsteady and compressible flow calculations with large pressure drop where inertia force is important. The presented calculations in this paper are for water flow. On the other hand, in the case of minor pressure drop in the networks for distribution of gaseous fluids it is possible to treat such gases as incompressible, i.e. as water. Some different approaches exist but the problem is not much different because the resistances in the networks for gas distribution depend also on flow as it is in the case of the distribution of liquids (Brkić 2011cd).

Improved Hardy Cross method. The original Hardy Cross method is some sort of single adjustment method which threats every single equation related to the loops in the network sequentially while the improved version treats the whole network system and related system of equations simultaneously (similar approach is used in the nodeloop method). The Hardy Cross iterative method with its modification by Epp and Fowler (1970) today is widely used for calculation of fluid flow through looped network of pipes. In both version of the Hardy Cross method, corrections of flow $\Delta \mathrm{Q}$ are calculated in every iteration rather than flow $\mathrm{Q}$ directly (Figure 1 - right). These corrections should be added to or subtracted from the flow calculated in previous iteration according to specific algebraic rules (Brkić 2009; Corfield et al. 1974). In the both versions of the Hardy Cross method, the original and the improved, the main
problem for students would be how to choose the correct algebraic sigh in certain cases
in order to add calculated correction of flow to the flow calculated in the previous
iteration. This problem is dverwhelmed by introduction of the node-loop method (here
shown in part A of the project). The improved Hardy Cross method will be used in the
example; part B for diameter optimisation. Similar as in direct problem of calculation of flow distribution, in the optimisation

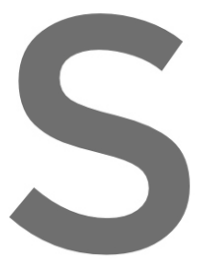

Register for free at httpsk/ www scipedia com to download the version with part B.

The node-loop method. This method unites the matrix of loops and of nodes which makes possible direct calculation of final flow $Q$ in each of the iterations (Figure 1 left), and not anymore through the correction of flow $\Delta \mathrm{Q}$ as in the Hardy Cross method (Figure 1 - right). The main strength of the node-loop method introduced by Wood and Charles (1972) does not reflect in noticeably reduced number of iteration compared to the improved Hardy Cross method. The main advantage of this method is in its the capability to solve directly the pipe flow rates (one step less). Wood and Rayes (1981) later introduced some further improvements in the node-loop method. The node-loop method will be used in the example; part A, for flow calculation.

Matrix calculus in spreadsheet environment. To enter matrix, i.e. array formula in Microsoft Excel, the range of matrix must be selected starting with the cell in which formula is typed. Then function button F2 at keyboard has to be pressed following with CTRL+SHIFT+ENTER. If the formula is not entered as an array formula, the single result will appear (first row and column of matrix). Following this, Microsoft Excel can be used efficiently as a tool for solution to the presented problems. 


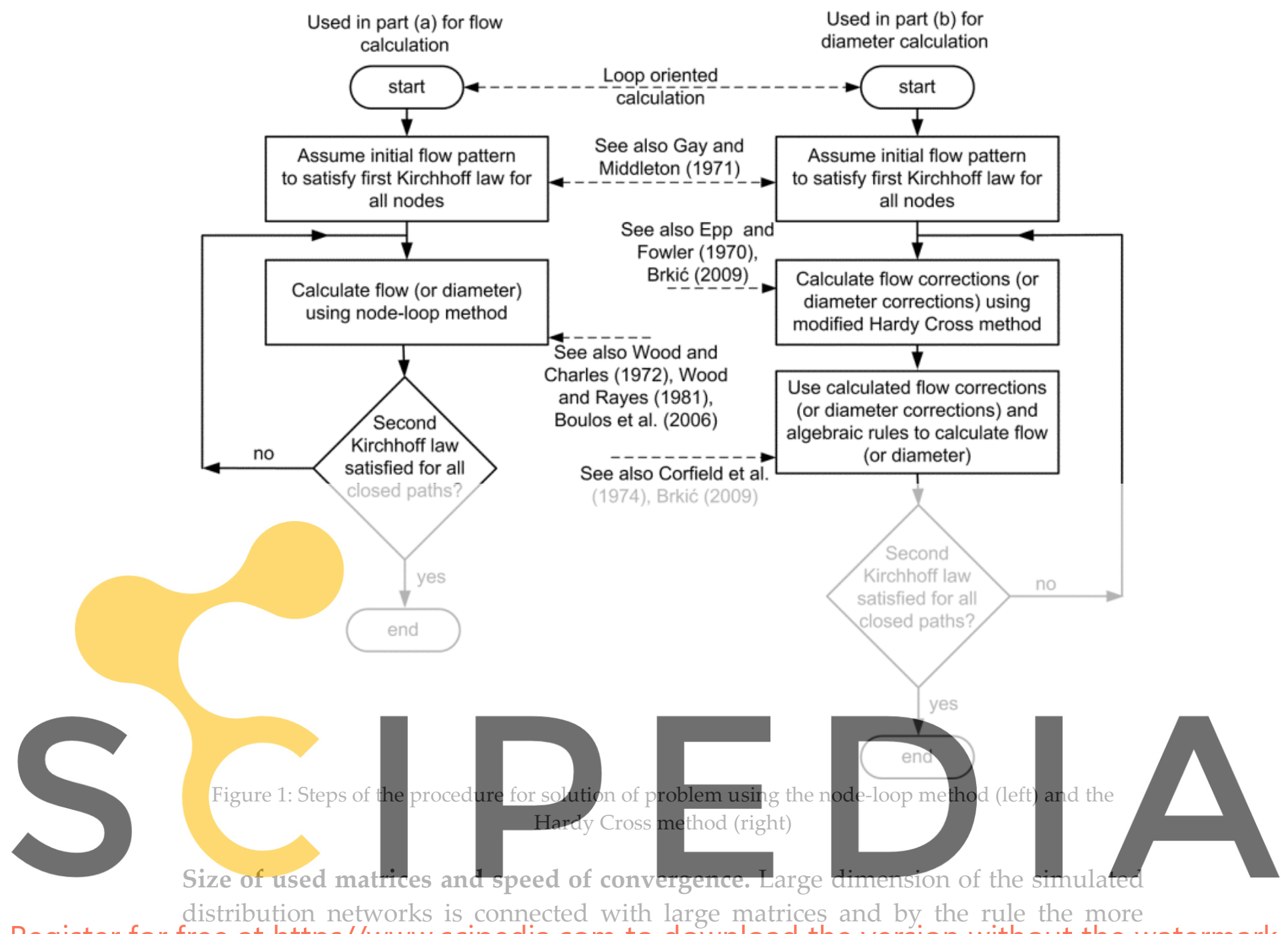

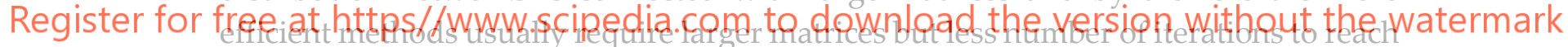

balanced solution. It is worth to point out that the original Hardy Cross method is much slower in case of large-scale networks compared with the methods here presented through the educational example. The original Hardy Cross method can be used for simple networks but only for educational purposes as a first step toward better understanding of the main principles of calculation.

Additional methods. Another methods are also available (Shamir and Howard 1968; Hamam and Brameller 1971; Walski 1984, 2006; Todini and Pilati 1988; Boulos et al. 2006; Ormsbee 2006; Brkić 2011d). They also can be used in work with students.

Possible additional tasks for students. It is possible to choose randomly pressure drop pattern to satisfy the second Kirchhoff's law for every loop and then through iterative procedure to find flow balance for every node. Shamir and Howard (1968) reformulated the original Hardy Cross method to solve node equations and not any more loop equations. Methods based on node equations are less reliable and have to be employed with caution. The convergence of loop methods is faster than the convergence of nodal methods since the error functions have the form close to quadratic instead of square root. Students can also use nodal approach to solve the assigned problems. 


\section{Formulation of problems and details about specific tasks to be assigned}

The presented problem which students have to solve has two parts:

A. to find flows using the node-loop method in all conduits for maximal node consumption (simulation problem), and

B. to optimize pipe diameters for flow velocity using the improved Hardy Cross method, for $1 \mathrm{~m} / \mathrm{h}$ (optimization problem) for calculated flows in the part A of the project.

Huddleston et al. (2004) discussed the use of spreadsheet tools to introduce students to fundamental concepts of water distribution network analysis by using an illustration network which is a variation of the network presented by Wood and Charles (1972). This network will be used in this paper. Both presented students' problems can be solved using Microsoft Excel.

Goal is that each student fully understand all methods prescribed by curriculum, and that will be accomplished during one twelve-week semester if each student solve simple network problem using all available methods at least once.

To design or analyse any water distribution system, the pipe lengths and roughness, as well as fluid properties, must be defined. The kinematic viscosity of water is prescribed as $\mu=1.0037 \cdot 10^{-6} \mathrm{~m}^{2} / \mathrm{s}$, and absolute roughness of pipes is estimated at $\varepsilon=0.00026 \mathrm{~m}$ (Huddleston et al. 2004), both will be used as inputs for the Colebrook's formula. Pressures will be expressed in $\mathrm{Pa}$, not in meter equivalents. The network is in
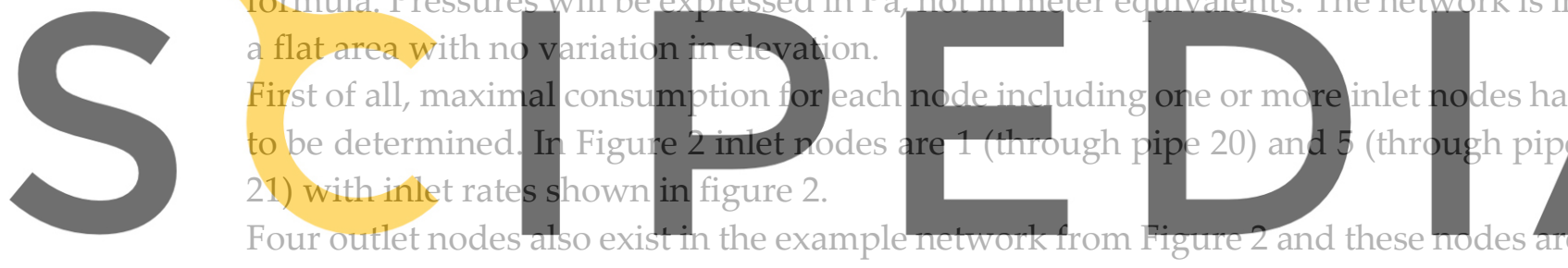

4, 6, 9 and 11. Outlet flow rates for these nodes are also shown in Figure 2. All other

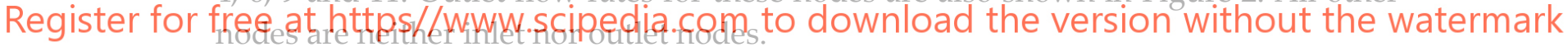

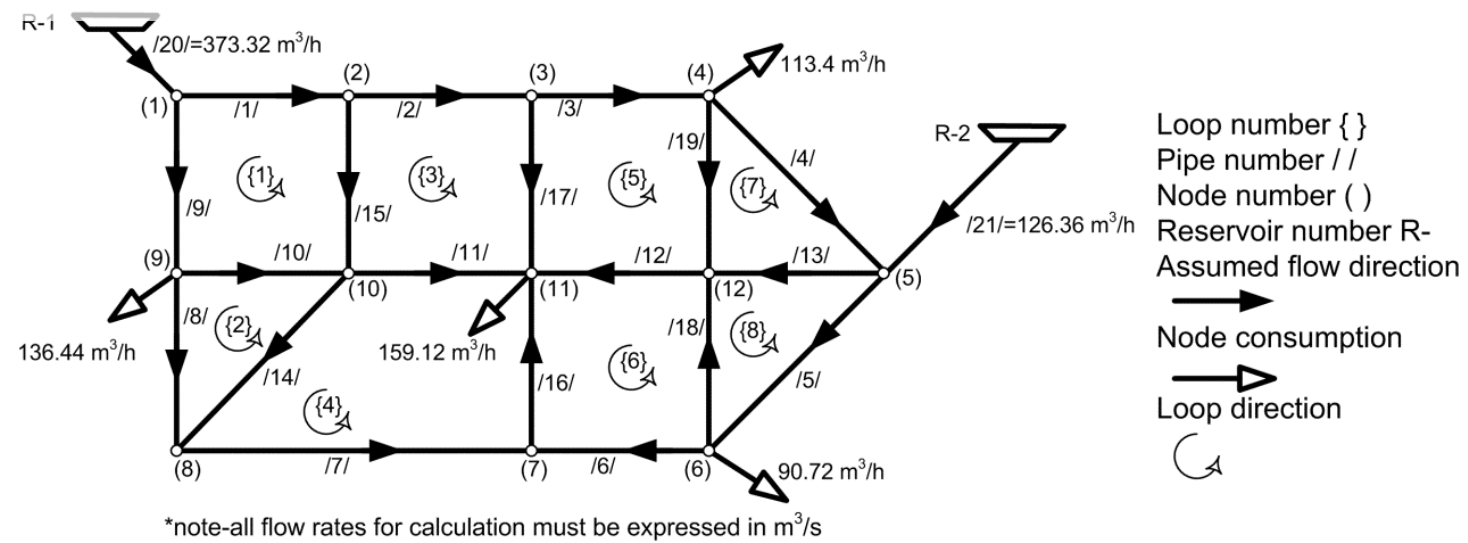

Figure 2: Hydraulic network for example problem

Tasks for students. The node-loop method for flow calculation, as part A of students' project and the improved (modified) Hardy Cross method, as part B are chosen to be presented. Both methods are more efficient compared to the original Hardy Cross method. In simulation problem, part A, calculation of flow rates for known pipe diameters will be performed, and as second problem, part B, pipe diameters will be 
optimized after recommended flow velocity. Solution of simulation problem; part A, is unique for the known and locked up values of pipe diameters, node inputs and node consumptions. Optimization problem; part B, has unique results for locked up values of flow rates only if the flow velocities per pipes are also locked up.

Possible additional tasks for students. Whole calculation can be done in MATLAB which is the software developed especially for matrix calculation (Ćojbašić and Brkić 2013; Brkić and Ćojbašić 2016).

\subsection{Part A of design project; Flow rates calculation using the node-loop method} In this part first assumed flow are chosen to satisfy first Kirchhoff's law (5). Pipe diameters and node input and output cannot be changed during the iterative procedure. Goal is to find final flow distribution for pipeline system from Figure 2. Pipe lengths and pipes diameters are listed in Table 1 together with the final solutions of flow. The final flows do not depend on first assumed water flows per pipes as shown by Gay and Middleton (1971). The solution is unique for chosen system. The final flows listed in Table 1 are those for which the second Kirchhoff's law is satisfied for all loops. Final flows are those which values are not changed between two successive iterations (must be satisfied for flow in each pipe).
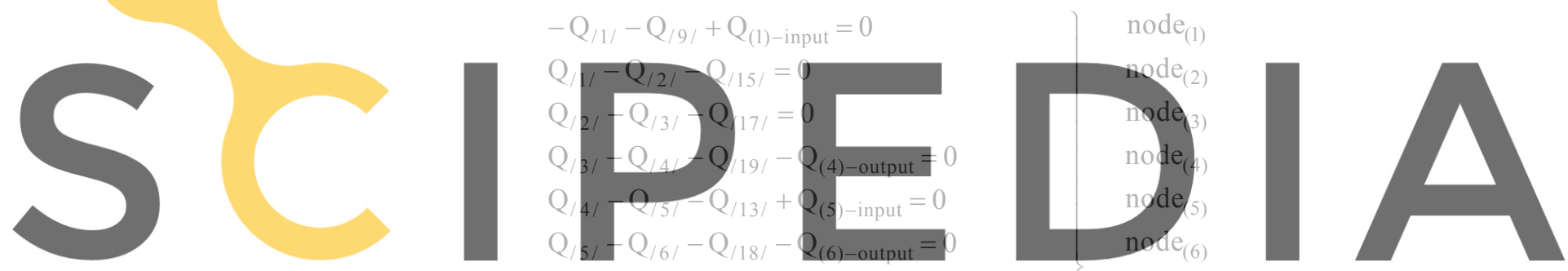

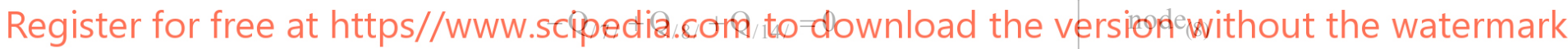

$$
\begin{array}{l|c}
-\mathrm{Q}_{/ 8 /}+\mathrm{Q}_{/ 9 /}-\mathrm{Q}_{/ 10 /}-\mathrm{Q}_{(9)-\text { output }}=0 & \operatorname{mode}_{(9)} \\
\mathrm{Q}_{/ 10 /}-\mathrm{Q}_{/ 11 /}-\mathrm{Q}_{/ 14 /}+\mathrm{Q}_{/ 15 /}=0 & \operatorname{node}_{(10)} \\
\mathrm{Q}_{/ 11 /}+\mathrm{Q}_{/ 12 /}+\mathrm{Q}_{/ 16 /}+\mathrm{Q}_{/ 17 /}-\mathrm{Q}_{(11)-\text { output }}=0 & \operatorname{node}_{(11)} \\
-\mathrm{Q}_{/ 12 /}+\mathrm{Q}_{/ 13 /}+\mathrm{Q}_{/ 18 /}+\mathrm{Q}_{/ 19 /}=0 & \operatorname{node}_{(12)}-\text { ref. }
\end{array}
$$

Q-volumetric flow rate $\left(\mathrm{m}^{3} / \mathrm{sec}\right)$.

Twelve node equations (5) can be noted in matrix form (6). One node from (5) has to be noted as "referent", and hence must be omitted from the so called the node matrix (6). The node matrix with all nodes included is not linearly independent. To obtain linear independence any row of the node matrix has to be omitted (to be chosen arbitrary). No information on the topology in that way will be lost. Node 12 is chosen as referent and hence will be virtually omitted from the calculation.

An alternative approach would be to introduce so called pseudo-loop in the system (close the path via reservoirs where closed paths will have a null total energy loss by definition, while opened paths, i.e. pseudo-loops will have an energy loss dictated by the flow condition at the path end points). Approach with pseudo-loop can be used also for learning and can be also assigned as Possible additional tasks for students (for the pseudo-loop approach see Boulos et al. 2006). 
$[\mathrm{N}]=\left[\begin{array}{ccccccccccccccccccc}-1 & 0 & 0 & 0 & 0 & 0 & 0 & 0 & -1 & 0 & 0 & 0 & 0 & 0 & 0 & 0 & 0 & 0 & 0 \\ 1 & -1 & 0 & 0 & 0 & 0 & 0 & 0 & 0 & 0 & 0 & 0 & 0 & 0 & -1 & 0 & 0 & 0 & 0 \\ 0 & 1 & -1 & 0 & 0 & 0 & 0 & 0 & 0 & 0 & 0 & 0 & 0 & 0 & 0 & 0 & -1 & 0 & 0 \\ 0 & 0 & 1 & -1 & 0 & 0 & 0 & 0 & 0 & 0 & 0 & 0 & 0 & 0 & 0 & 0 & 0 & 0 & -1 \\ 0 & 0 & 0 & 1 & -1 & 0 & 0 & 0 & 0 & 0 & 0 & 0 & -1 & 0 & 0 & 0 & 0 & 0 & 0 \\ 0 & 0 & 0 & 0 & 1 & -1 & 0 & 0 & 0 & 0 & 0 & 0 & 0 & 0 & 0 & 0 & 0 & -1 & 0 \\ 0 & 0 & 0 & 0 & 0 & 1 & 1 & 0 & 0 & 0 & 0 & 0 & 0 & 0 & 0 & -1 & 0 & 0 & 0 \\ 0 & 0 & 0 & 0 & 0 & 0 & -1 & 1 & 0 & 0 & 0 & 0 & 0 & 1 & 0 & 0 & 0 & 0 & 0 \\ 0 & 0 & 0 & 0 & 0 & 0 & 0 & -1 & 1 & -1 & 0 & 0 & 0 & 0 & 0 & 0 & 0 & 0 & 0 \\ 0 & 0 & 0 & 0 & 0 & 0 & 0 & 0 & 0 & 1 & -1 & 0 & 0 & -1 & 1 & 0 & 0 & 0 & 0 \\ 0 & 0 & 0 & 0 & 0 & 0 & 0 & 0 & 0 & 0 & 1 & 1 & 0 & 0 & 0 & 1 & 1 & 0 & 0\end{array}\right]$

In previous matrix [N], 1 means that pipe is connected to node and that the arrow in Figure 2 is pointing toward node in the first iteration for the first assumed flow; -1 means opposite and 0 means that pipe is not connected to related node. In $[\mathrm{N}]$ matrix (6), rows represent nodes while columns represent pipes. Of course, terms in this matrix will be changed during the iteration process, i.e. only terms with 1 or -1 can change their signs, while terms with 0 always remain unchanged for this topology of network (Figure 2).

To introduce the node-loop method, beside the above presented node matrix, the loop matrix must be formed using eight loop equations (7).
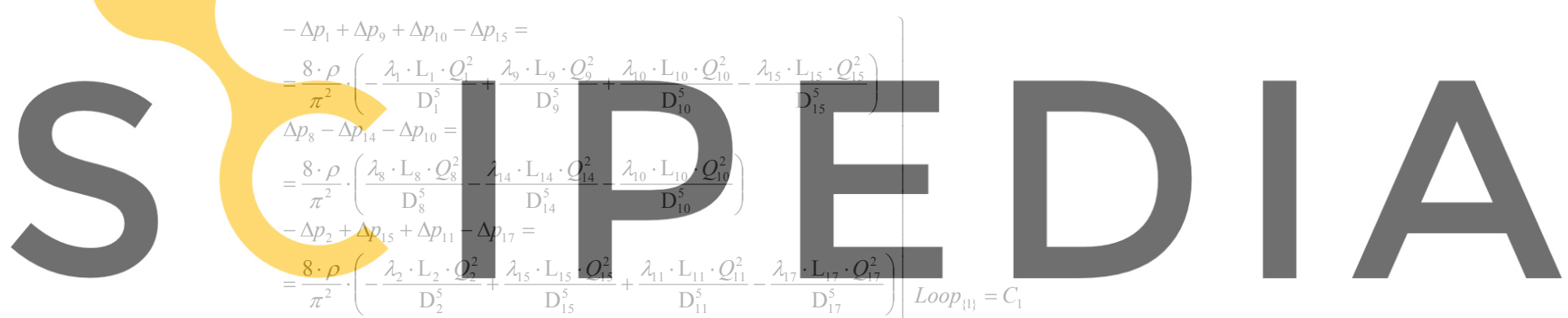

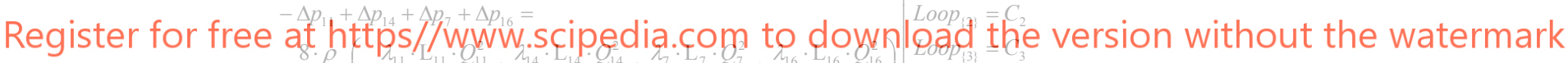

$$
\begin{aligned}
& -\Delta p_{3}+\Delta p_{17}-\Delta p_{12}-\Delta p_{19}= \\
& =\frac{8 \cdot \rho}{\pi^{2}} \cdot\left(-\frac{\lambda_{3} \cdot \mathrm{L}_{3} \cdot Q_{3}^{2}}{\mathrm{D}_{3}^{5}}+\frac{\lambda_{17} \cdot \mathrm{L}_{17} \cdot Q_{17}^{2}}{\mathrm{D}_{17}^{5}}-\frac{\lambda_{12} \cdot \mathrm{L}_{12} \cdot Q_{12}^{2}}{\mathrm{D}_{12}^{5}}-\frac{\lambda_{19} \cdot \mathrm{L}_{19} \cdot Q_{19}^{2}}{\mathrm{D}_{19}^{5}}\right)\left(\begin{array}{l}
L_{0 o p}\{\}=C_{5} \\
\operatorname{Loop}_{\{6\}}=C_{6} \\
-\Delta p_{6}+\Delta p_{12}-\Delta p_{16}+\Delta p_{18}= \\
=\frac{8 \cdot \rho}{\pi^{2}} \cdot\left(-\frac{\lambda_{6} \cdot \mathrm{L}_{6} \cdot Q_{6}^{2}}{\mathrm{D}_{6}^{5}}+\frac{\lambda_{12} \cdot \mathrm{L}_{12} \cdot Q_{12}^{2}}{\mathrm{D}_{12}^{5}}-\frac{\lambda_{16} \cdot \mathrm{L}_{16} \cdot Q_{16}^{2}}{\mathrm{D}_{16}^{5}}+\frac{\lambda_{18} \cdot \mathrm{L}_{18} \cdot Q_{18}^{2}}{\mathrm{D}_{18}^{5}}\right) \\
-\Delta p_{4}+\Delta p_{19}-\Delta p_{13}= \\
\operatorname{Loop}_{\{8\}}=C_{8} \\
=\frac{8 \cdot \rho}{\pi^{2}} \cdot\left(-\frac{\lambda_{4} \cdot \mathrm{L}_{4} \cdot Q_{4}^{2}}{\mathrm{D}_{4}^{5}}+\frac{\lambda_{19} \cdot \mathrm{L}_{19} \cdot Q_{19}^{2}}{\mathrm{D}_{19}^{5}}-\frac{\lambda_{13} \cdot \mathrm{L}_{13} \cdot Q_{13}^{2}}{\mathrm{D}_{13}^{5}}\right) \\
\Delta p_{13}-\Delta p_{18}-\Delta p_{5}= \\
=\frac{8 \cdot \rho}{\pi^{2}} \cdot\left(\frac{\lambda_{13} \cdot \mathrm{L}_{13} \cdot Q_{13}^{2}}{\mathrm{D}_{13}^{5}}-\frac{\lambda_{18} \cdot \mathrm{L}_{18} \cdot Q_{18}^{2}}{\mathrm{D}_{18}^{5}}-\frac{\lambda_{5} \cdot \mathrm{L}_{5} \cdot Q_{5}^{2}}{\mathrm{D}_{5}^{5}}\right)
\end{array}\right)
\end{aligned}
$$

$\Delta \mathrm{p}$-pressure drop $(\mathrm{Pa})$;

$\rho$-density of fluid $\left(\mathrm{kg} / \mathrm{m}^{3}\right)$;

$\lambda$-flow friction factor, known also as Darcy, Darcy-Weisbach or Moody friction factor (dimensionless);

L-pipe length (m);

Q-volumetric flow rate $\left(\mathrm{m}^{3} / \mathrm{sec}\right)$;

D-inner pipe diameter $(\mathrm{m})$; and

$\pi$-Ludolph number, $\pi \approx 3.1415$. 
Pressure drop in pipes is calculated using the Darcy-Weisbach scheme, and the Darcy friction factor $(\lambda)$ is calculated after the well-known implicit Colebrook's relation. The loop matrix [L] can be noted as follow (8):

$$
[\mathrm{L}]=\left[\begin{array}{ccccccccccccccccccc}
-1 & 0 & 0 & 0 & 0 & 0 & 0 & 0 & 1 & 1 & 0 & 0 & 0 & 0 & -1 & 0 & 0 & 0 & 0 \\
0 & 0 & 0 & 0 & 0 & 0 & 0 & 1 & 0 & -1 & 0 & 0 & 0 & -1 & 0 & 0 & 0 & 0 & 0 \\
0 & -1 & 0 & 0 & 0 & 0 & 0 & 0 & 0 & 0 & 1 & 0 & 0 & 1 & 0 & -1 & 0 & 0 & 0 \\
0 & 0 & 0 & 0 & 0 & 0 & 1 & 0 & 0 & 0 & -1 & 0 & 0 & 1 & 0 & 1 & 0 & 0 & 0 \\
0 & 0 & -1 & 0 & 0 & 0 & 0 & 0 & 0 & 0 & 0 & -1 & 0 & 0 & 0 & 0 & 1 & 0 & -1 \\
0 & 0 & 0 & 0 & 0 & -1 & 0 & 0 & 0 & 0 & 0 & 1 & 0 & 0 & 0 & -1 & 0 & 1 & 0 \\
0 & 0 & 0 & -1 & 0 & 0 & 0 & 0 & 0 & 0 & 0 & 0 & -1 & 0 & 0 & 0 & 0 & 0 & 1 \\
0 & 0 & 0 & 0 & -1 & 0 & 0 & 0 & 0 & 0 & 0 & 0 & 1 & 0 & 0 & 0 & 0 & -1 & 0
\end{array}\right]
$$

In the loop matrix, rows represent loops and columns as in the node matrix, represent pipes. The sign for the term is adopted as positive, i.e. as 1 if the assumed flow is clockwise, or as negative, i.e. -1 if it is counter-clockwise relative to the loop.

The first Kirchhoff's law in matrix form can be noted as $[\mathrm{N}] \mathrm{x}[\mathrm{Q}]=0$, while the second one can be noted as $[\mathrm{L}] \mathrm{x}[\Delta \mathrm{p}]=0$, where $[\mathrm{Q}]=\left[\mathrm{Q} / 1 /, \mathrm{Q}_{/ 2 /}, \cdots \cdots \cdots, \mathrm{Q}_{/ 19 /}\right]^{\mathrm{T}}$ transposes matrix of flow per pipe, and $\left[\Delta \mathrm{p}_{1}, \Delta \mathrm{p}_{2}, \cdots \cdots \cdot . \cdot \Delta \mathrm{p}_{8}\right]^{\mathrm{T}}$ transposes matrix of algebraic sums of pressure drops per loops.

For the node-loop method calculation, the node-loop matrix [NL] has to be formed to unite both, the node matrix $[\mathrm{N}]$ and the loop matrix [L]. First eleven rows in [NL] matrix are from $[\mathrm{N}]$, and next eight rows are from [L] where each term is multiplied by first derivative (for each pipe) of $\Delta \mathrm{p}$ where $\mathrm{Q}$ is treated as variable (9):

$F^{\prime}=\frac{\partial(\Delta p)}{\partial Q}=\frac{\partial\left(\frac{8 \cdot \rho \cdot \lambda \cdot \mathrm{L} \cdot Q \cdot|Q|}{\pi^{2} \cdot \mathrm{D}^{5}}\right)}{\partial Q}=\frac{\partial(R \cdot Q \cdot|Q|)}{\partial Q}=\frac{16 \cdot \rho \cdot \lambda \cdot \mathrm{L} \cdot|Q|}{\pi^{2} \cdot \mathrm{D}^{5}}=2 \cdot R \cdot|Q|$

$\mathrm{F}^{\prime}$-first derivative of function;

Q-volumetric flow rate $\left(\mathrm{m}^{3} / \mathrm{sec}\right)$;

$\partial$-partial derivative, here $\mathrm{Q}$ is variable;

$\Delta$ p-pressure drop $(\mathrm{Pa})$;

$\rho$-density of fluid $\left(\mathrm{kg} / \mathrm{m}^{3}\right)$;

$\lambda$-flow friction factor, known also as Darcy, Darcy-Weisbach or Moody friction factor (dimensionless);

L-pipe length (m);

D-inner pipe diameter $(\mathrm{m})$;

R- auxiliary equivalent of resistance; and $\pi$-Ludolph number, $\pi \approx 3.1415$.

After that solution for the unknown, flow rates have to be calculated using (10):

$$
[\mathrm{Q}]=\operatorname{inv}[\mathrm{NL}] \times[\mathrm{V}]
$$

For constitution of matrix [V], the rules will be shown in example (11). 
In matrix $[\mathrm{V}]$, the sign in front of $(\mathrm{Q})$ differentiate input and output nodes.

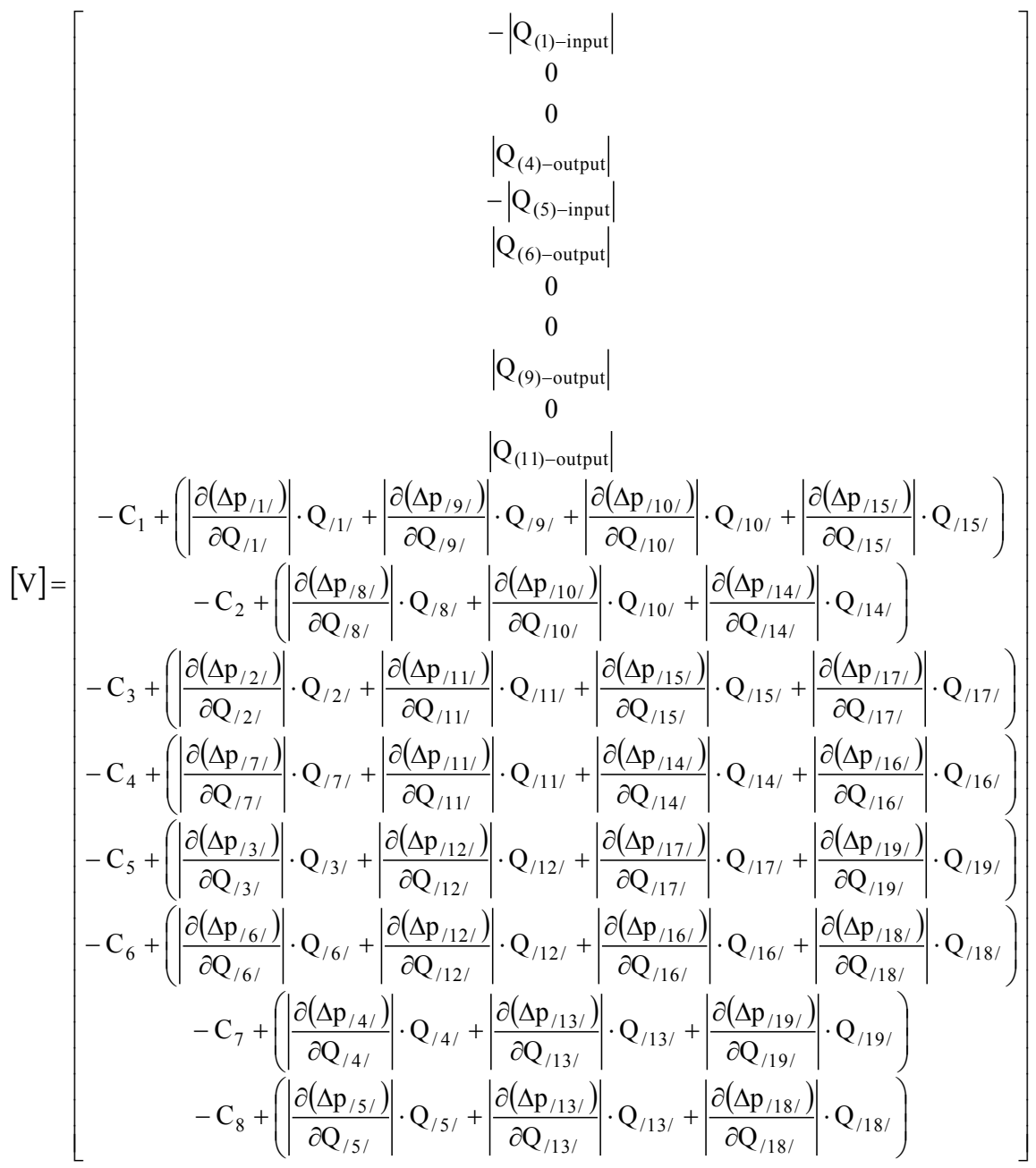

$\Delta$ p-pressure drop $(\mathrm{Pa})$;

Q-volumetric flow rate $\left(\mathrm{m}^{3} / \mathrm{sec}\right)$;

$\partial$-partial derivative, $\mathrm{Q}$ is variable; and

C-as defined in eq. (7).

Matrix [NL] is made using matrix [N] and [L] where in matrix [L] all terms are multiplied by appropriate first derivative of pressure drop function (12).

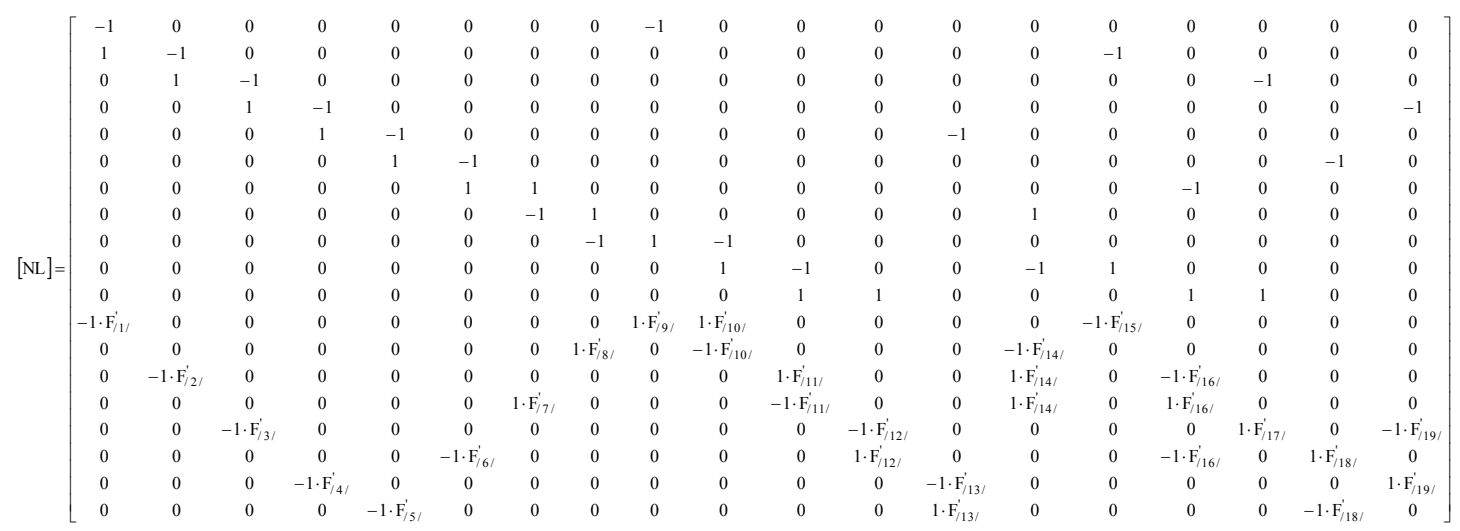

$\mathrm{F}^{\prime}$-first derivative of function; as defined in Eq. (9). 
The sign minus in front of some terms in resulting matrix [Q] means that sing preceding this term in the previous iteration must be changed (calculated flow direction in this pipe has been changed). Nine iterations are enough for the calculation of water network from Figure 2 (algebraic sum of pressure drops for all contours is approximately zero).

Data necessary for calculation are listed in Table 1.

Table 1: Data for example problem from Figure 2 /part A of students' design project/

\begin{tabular}{|c|c|c|c|c|c|}
\hline \multirow{2}{*}{ Pipe number } & \multirow{2}{*}{ Diameter (m) } & \multirow{2}{*}{ Length (m) } & \multicolumn{2}{|c|}{ Flow rate $\left(\mathrm{m}^{3} / \mathrm{h}\right)$} & \multirow{2}{*}{ Velocity $(\mathrm{m} / \mathrm{s})$} \\
\hline & & & Initial & Final & \\
\hline$/ 1 /$ & 0.305 & 457.2 & 173.32 & 200.67 & 0.76 \\
\hline$/ 2 /$ & 0.203 & 304.8 & 150 & 144.10 & 1.24 \\
\hline$/ 3 /$ & 0.203 & 365.8 & 130 & 59.29 & 0.51 \\
\hline$/ 4 /$ & 0.203 & 609.6 & 6.6 & -37.23 & 0.32 \\
\hline$/ 5 /$ & 0.203 & 853.4 & 100 & 31.27 & 0.27 \\
\hline$/ 6 /$ & 0.203 & 335.3 & 0.28 & -45.17 & 0.39 \\
\hline$/ 7 /$ & 0.203 & 304.8 & 16.88 & 53.90 & 0.46 \\
\hline$/ 8 /$ & 0.203 & 762.0 & 13.56 & 34.82 & 0.30 \\
\hline$/ 9 /$ & 0.203 & 243.8 & 200 & 172.65 & 1.48 \\
\hline$/ 10 /$ & 0.152 & 396.2 & 50 & 1.39 & 0.02 \\
\hline$/ 11 /$ & 0.152 & 304.8 & 70 & 38.88 & 0.60 \\
\hline$/ 12 /$ & 0.254 & 335.3 & 51.96 & 26.70 & 0.15 \\
\hline$/ 13 /$ & 0.254 & 304.8 & 32.96 & 57.86 & 0.32 \\
\hline$/ 14 /$ & 0.152 & 548.6 & 3.32 & 19.09 & 0.29 \\
\hline$/ 15 /$ & 0.152 & 335.3 & 23.32 & 56.57 & 0.87 \\
\hline$/ 16 /$ & 0.152 & 548.6 & 17.16 & 8.73 & 0.13 \\
\hline$/ 17 /$ & 0.254 & 365.9 & 20 & 84.81 & 0.46 \\
\hline$/ 18 /$ & 0.152 & 548.6 & 9 & -14.28 & 0.22 \\
\hline$/ 19 /$ & 0.152 & 396.2 & 10 & -16.88 & 0.26 \\
\hline
\end{tabular}

Presented example in MS Excel; Part A is available as electronic annex attached to the electronic version of this paper (Table S1).

\subsection{Part B of design project; Pipe diameter optimisation using Improved Hardy Cross method}

In the problem of optimization of pipe diameters, flow rates calculated in 'part A' of the students' design project are not any more treated as variable. These flow rates in the next calculation will be locked up, while the pipes diameters will be treated as variable (13).

$\frac{\partial(\Delta p)}{\partial D}=\frac{\partial\left(\frac{8 \cdot \rho \cdot \lambda \cdot \mathrm{L} \cdot Q \cdot|Q|}{\pi^{2} \cdot \mathrm{D}^{5}}\right)}{\partial D}=\frac{\partial\left(R \cdot D^{-5}\right)}{\partial D}=\frac{-40 \cdot \rho \cdot \lambda \cdot \mathrm{L} \cdot Q \cdot|Q|}{\pi^{2} \cdot \mathrm{D}^{6}}=-5 \cdot R \cdot D^{-6}$

$\mathrm{F}^{\prime}$-first derivative of function;

D-inner pipe diameter $(\mathrm{m})$; 
$\partial$-partial derivative, here $\mathrm{D}$ is variable;

$\Delta \mathrm{p}$-pressure drop $(\mathrm{Pa})$;

Q-volumetric flow rate $\left(\mathrm{m}^{3} / \mathrm{sec}\right)$;

$\rho$-density of fluid $\left(\mathrm{kg} / \mathrm{m}^{3}\right)$;

$\lambda$-flow friction factor, known also as Darcy, Darcy-Weisbach or Moody friction factor (dimensionless);

L-pipe length (m);

R-auxiliary equivalent of resistance; and

$\pi$-Ludolph number, $\pi \approx 3.1415$.

According to the improved Hardy Cross method, correction for pipe diameters for each pipe which belong to the related loop is (14).

$\left[\begin{array}{cccccccc}\frac{\partial \mathrm{C}_{1}(\mathrm{D})}{\partial \mathrm{D}_{\{1\}}} & -\frac{\partial \Delta \mathrm{p}_{10}(\mathrm{D})}{\partial \mathrm{D}_{\{1\}}} & -\frac{\partial \Delta \mathrm{p}_{15}(\mathrm{D})}{\partial \mathrm{D}_{\{1\}}} & 0 & 0 & 0 & 0 & 0 \\ -\frac{\partial \Delta \mathrm{p}_{10}(\mathrm{D})}{\partial \mathrm{D}_{\{2\}}} & \frac{\partial \mathrm{C}_{2}(\mathrm{D})}{\partial \mathrm{D}_{\{2\}}} & 0 & -\frac{\partial \Delta \mathrm{p}_{14}(\mathrm{D})}{\partial \mathrm{D}_{\{2\}}} & 0 & 0 & 0 & 0 \\ -\frac{\partial \Delta \mathrm{p}_{10}(\mathrm{D})}{\partial \mathrm{D}_{\{3\}}} & 0 & \frac{\partial \mathrm{C}_{3}(\mathrm{D})}{\partial \mathrm{D}_{\{3\}}} & -\frac{\partial \Delta \mathrm{p}_{11}(\mathrm{D})}{\partial \mathrm{D}_{\{3\}}} & -\frac{\partial \Delta \mathrm{p}_{17}(\mathrm{D})}{\partial \mathrm{D}_{\{3\}}} & 0 & 0 & 0 \\ 0 & -\frac{\partial \Delta \mathrm{p}_{14}(\mathrm{D})}{\partial \mathrm{D}_{\{4\}}} & -\frac{\partial \Delta \mathrm{p}_{11}(\mathrm{D})}{\partial \mathrm{D}_{\{4\}}} & \frac{\partial \mathrm{C}_{4}(\mathrm{D})}{\partial \mathrm{D}_{\{4\}}} & 0 & -\frac{\partial \Delta \mathrm{p}_{16}(\mathrm{D})}{\partial \mathrm{D}_{\{4\}}} & 0 & 0 \\ 0 & 0 & -\frac{\partial \Delta \mathrm{p}_{17}(\mathrm{D})}{\partial \mathrm{D}_{\{3\}}} & 0 & \frac{\partial \mathrm{C}_{5}(\mathrm{D})}{\partial \mathrm{D}_{\{5\}}} & -\frac{\partial \Delta \mathrm{p}_{12}(\mathrm{D})}{\partial \mathrm{D}_{\{5\}}} & -\frac{\partial \Delta \mathrm{p}_{19}(\mathrm{D})}{\partial \mathrm{D}_{\{5\}}} & 0 \\ 0 & 0 & 0 & -\frac{\partial \Delta \mathrm{p}_{16}(\mathrm{D})}{\partial \mathrm{D}_{\{6\}}} & -\frac{\partial \Delta \mathrm{p}_{12}(\mathrm{D})}{\partial \mathrm{D}_{\{6\}}} & \frac{\partial \mathrm{C}_{6}(\mathrm{D})}{\partial \mathrm{D}_{\{6\}}} & 0 & -\frac{\partial \Delta \mathrm{p}_{18}(\mathrm{D})}{\partial \mathrm{D}_{\{6\}}} \\ 0 & 0 & 0 & 0 & -\frac{\partial \Delta \mathrm{p}_{19}(\mathrm{D})}{\partial \mathrm{D}_{\{7\}}} & 0 & \frac{\partial \mathrm{C}_{7}(\mathrm{D})}{\partial \mathrm{D}_{\{7\}}} & -\frac{\partial \Delta \mathrm{p}_{13}(\mathrm{D})}{\partial \mathrm{D}_{\{7\}}} \\ 0 & 0 & 0 & 0 & 0 & -\frac{\partial \Delta \mathrm{p}_{18}(\mathrm{D})}{\partial \mathrm{D}_{\{8\}}} & -\frac{\partial \Delta \mathrm{p}_{13}(\mathrm{D})}{\partial \mathrm{D}_{\{8\}}} & \frac{\partial \mathrm{C}_{8}(\mathrm{D})}{\partial \mathrm{D}_{\{8\}}}\end{array}\right] \times\left[\begin{array}{l}\Delta \mathrm{D}_{\{1\}} \\ \Delta \mathrm{D}_{\{2\}} \\ \Delta \mathrm{D}_{\{3\}} \\ \Delta \mathrm{D}_{\{4\}} \\ \Delta \mathrm{D}_{\{5\}} \\ \Delta \mathrm{D}_{\{6\}} \\ \Delta \mathrm{D}_{\{7\}} \\ \Delta \mathrm{D}_{\{8\}}\end{array}\right]=\left[\begin{array}{l}\mathrm{C}_{\{1\}} \\ \mathrm{C}_{\{2\}} \\ \mathrm{C}_{\{3\}} \\ \mathrm{C}_{\{4\}} \\ \mathrm{C}_{\{5\}} \\ \mathrm{C}_{\{6\}} \\ \mathrm{C}_{\{7\}} \\ \mathrm{C}_{\{8\}}\end{array}\right]$

$\Delta \mathrm{p}$-pressure drop $(\mathrm{Pa})$;

$\mathrm{D}$-inner pipe diameter $(\mathrm{m})$;

$\partial$-partial derivative, $\mathrm{D}$ is variable; and

C-as defined in eq. (7).

For example the term in the first row and the first column in the previous iteration, is (15):

$\frac{\partial \mathrm{C}_{1}(\mathrm{D})}{\partial \mathrm{D}_{\{1\}}}=\frac{\partial\left(\left|-\Delta \mathrm{p}_{1}\left(\mathrm{D}_{1}\right)\right|+\left|\Delta \mathrm{p}_{9}\left(\mathrm{D}_{9}\right)\right|+\left|\Delta \mathrm{p}_{10}\left(\mathrm{D}_{10}\right)\right|+\left|-\Delta \mathrm{p}_{15}\left(\mathrm{D}_{15}\right)\right|\right)}{\partial \mathrm{D}_{\{1\}}}=$
$=\frac{-40 \cdot \rho}{\pi^{2}} \cdot\left(\left|-\frac{\lambda_{1} \cdot \mathrm{L}_{1} \cdot \mathrm{Q}_{1}^{2}}{\mathrm{D}_{1}^{6}}\right|+\left|\frac{\lambda_{9} \cdot \mathrm{L}_{9} \cdot \mathrm{Q}_{9}^{2}}{\mathrm{D}_{9}^{6}}\right|+\left|\frac{\lambda_{10} \cdot \mathrm{L}_{10} \cdot \mathrm{Q}_{10}^{2}}{\mathrm{D}_{10}^{6}}\right|+\left|-\frac{\lambda_{15} \cdot \mathrm{L}_{15} \cdot \mathrm{Q}_{15}^{2}}{\mathrm{D}_{15}^{6}}\right|\right)$

$\Delta \mathrm{p}$-pressure drop $(\mathrm{Pa})$;

Q-volumetric flow rate $\left(\mathrm{m}^{3} / \mathrm{sec}\right)$;

$\rho$-density of fluid $\left(\mathrm{kg} / \mathrm{m}^{3}\right)$;

$\lambda$-flow friction factor, known also as Darcy, Darcy-Weisbach or Moody friction factor (dimensionless);

L-pipe length (m);

D-inner pipe diameter $(\mathrm{m})$;

$\partial$-partial derivative, $\mathrm{D}$ is variable; and

C-as defined in eq. (7). 
First matrix in the previous relation (14) is symmetrical; for example (16):

$$
-\frac{\partial \Delta \mathrm{p}_{10}(\mathrm{D})}{\partial \mathrm{D}_{\{1\}}}=-\frac{\partial \Delta \mathrm{p}_{10}(\mathrm{D})}{\partial \mathrm{D}_{\{2\}}}
$$

$\Delta \mathrm{p}$-pressure drop $(\mathrm{Pa})$;

D-inner pipe diameter $(\mathrm{m})$; and

$\partial$-partial derivative, $\mathrm{D}$ is variable.

This is because pipe 10 is mutual for two adjacent loops (loop $\{1\}$ and loop $\{2\}$ ).

Matrix reformulation of the original Hardy Cross method can be made if all terms in the first matrix (14) with exception of those from the main diagonal, are equalized with zero (this could be assigned as Possible additional tasks for students). Rules for determination of algebraic signs for the corrections of diameter can be seen in Brkić (2009) and in Corfield et al. (1974).

Calculated diameters (optimized for velocity of $1 \mathrm{~m} / \mathrm{s}$ and for the locked up values of flow rates calculated in part a) will be listed in Table 2 .

Table 2: Data for example problem from Figure 1/part B of students' design project/

\begin{tabular}{|c|c|c|c|c|c|c|}
\hline \multirow{2}{*}{ Pipe number } & \multirow{2}{*}{$\begin{array}{c}\text { aFlow rate } \\
\left(\mathrm{m}^{3} / \mathrm{h}\right)\end{array}$} & \multirow{2}{*}{$\begin{array}{l}\text { Length } \\
(\mathrm{m})\end{array}$} & \multicolumn{2}{|c|}{ Diameter (m) } & \multicolumn{2}{|c|}{ Velocity $(\mathrm{m} / \mathrm{s})$} \\
\hline & & & ${ }^{\mathrm{b}}$ Initial & cFinal & Initial & Final \\
\hline$/ 1 /$ & 200.67 & 457.2 & 0.2664 & 0.2483 & 0.76 & 1.15 \\
\hline$/ 2 /$ & 144.10 & 304.8 & 0.2257 & 0.2025 & 1.24 & 1.24 \\
\hline $13 /$ & 59.29 & 365.8 & 0.1448 & 0.1417 & 0.51 & 1.04 \\
\hline /4/ & -37.23 & 609.6 & 0.1147 & 0.1125 & 0.32 & 1.04 \\
\hline $15 /$ & 31.27 & 853.4 & 0.1051 & 0.1043 & 0.27 & 1.02 \\
\hline $16 /$ & -45.17 & 335.3 & 0.1263 & 0.1236 & 0.39 & 1.05 \\
\hline $\mid 7 /$ & 53.90 & 304.8 & 0.1380 & 0.1690 & 0.46 & 0.67 \\
\hline $18 /$ & 34.82 & 762.0 & 0.1109 & 0.1173 & 0.30 & 0.89 \\
\hline /9/ & 172.65 & 243.8 & 0.2471 & 0.2651 & 1.48 & 0.87 \\
\hline$/ 10 /$ & 1.39 & 396.2 & 0.0221 & 0.0338 & 0.02 & 0.43 \\
\hline$/ 11 /$ & 38.88 & 304.8 & 0.1172 & 0.1094 & 0.60 & 1.15 \\
\hline$/ 12 /$ & 26.70 & 335.3 & 0.0971 & 0.0912 & 0.15 & 1.13 \\
\hline$/ 13 /$ & 57.86 & 304.8 & 0.1430 & 0.1460 & 0.32 & 0.96 \\
\hline$/ 14 /$ & 19.09 & 548.6 & 0.0821 & 0.1067 & 0.29 & 0.59 \\
\hline$/ 15 /$ & 56.57 & 335.3 & 0.1414 & 0.1465 & 0.87 & 0.93 \\
\hline /16/ & 8.73 & 548.6 & 0.0555 & 0.0893 & 0.13 & 0.39 \\
\hline$/ 17 /$ & 84.81 & 365.9 & 0.1731 & 0.1531 & 0.46 & 1.28 \\
\hline$/ 18 /$ & -14.28 & 548.6 & 0.0710 & 0.0746 & 0.22 & 0.91 \\
\hline$/ 19 /$ & -16.88 & 396.2 & 0.0772 & 0.0825 & 0.26 & 0.88 \\
\hline
\end{tabular}

athe minus (-) sign indicates that the flow direction is opposite to that shown in Figure 2, busing (17),

cthese are final calculated diameters, but real values must be adopted from the list of standard diameters (first larger if velocity is higher than $1 \mathrm{~m} / \mathrm{s}$ and first smaller if velocity is below $1 \mathrm{~m} / \mathrm{s}$ )

The flow rates are locked up, while the velocities are not (average velocity for all pipe are $1 \mathrm{~m} / \mathrm{s}$, but in particular pipes, speed have values slightly above or below optimized 
velocity values which in our case is $1 \mathrm{~m} / \mathrm{s}$ ). Diameters of pipes for known flow rates through pipes and fixed value of water velocity will be calculated after (17):

$$
D=\sqrt{\frac{4 \cdot|Q|}{v \cdot \pi}}
$$

D-inner pipe diameter $(\mathrm{m})$;

Q-volumetric flow rate $\left(\mathrm{m}^{3} / \mathrm{sec}\right)$;

$v$-velocity of fluid ( $\mathrm{m} / \mathrm{sec})$; and

$\pi$-Ludolph number, $\pi \approx 3.1415$.

These values of diameters (17) are initial for calculation while flows are final calculated

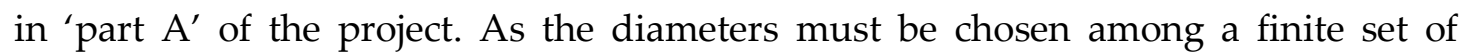
available nominal values, this optimization problem is highly combinatorial.

The presented example in MS Excel; Part B is available as electronic annex attached to the electronic version of this paper (Table S2).

\section{Teaching background and expected pedagogical benefits}

Some experiences from real classroom will be discussed. Teaching experience is mostly from Serbia but also some inputs are from Italy, the Netherlands and Belgium.

\subsection{Teaching background}

Formal engineering education has traditionally been delivered using the low technology lecturing method, in which lecturer and student meet face to face where lecturer is speaker while students are only listeners. It was largely an interaction between a student and the professor, with other students listening and occasional student-student involvement after class. Today, one of the tasks of good lecturer is to develop students' creative thinking. Some experience with implementation of the shown spreadsheet task will be discussed here.

Individual vs. Group learning. Creating a practical exam involves not only selecting what important is and organizing all material but also discussing the exam in a group settings. It is better if students not only discuss and solve their group tasks together, but also it is important that every student has his/her unique problem (like examples presented in this paper) which has to solve solely after discussion in the group. It is important for students to develop relationships with other class members and to form study group early in the course but to solve task individually (Hoffmann and McGuire 2010). In that way every member of such informal group of students has opportunity to learn and to discuss problems in a group but each of the individuals has to solve his/her problem and to take exams solely. Attempt to make problem for group of three or more students is not very wise because in such case usually only one or two students really try to solve the problem while the rest the group use some sort of "drone strategy" to avoid to participate.

Serbian experience. Advanced students in Serbia, from where the examples of students' project are taken, can earn additional ECTS (European Credit Transfer System) through tutorial work with other fellow students. Note that course has locked up number of ECTS, e.g. 6. Student can replace e.g. 0.5 ECTS with tutorial work instead 
to solve one task, or can improve his/her final grade. Every successful student at the end of semester has equal number of ECTS, but $10 \%$ of the best with outstanding performance with only minor errors has best grade $10 /$ ten/, etc., next $25 \%$ has grade 9/nine/, next $30 \%$ has grade $8 /$ eight/, next $25 \%$ grade $7 /$ seven/ and finally last $10 \%$ has mark 6/six/ which means that their work meets the minimum criteria. All other students have grade 5/five/ in the meaning fail with considerable further work required which can be done only in the next year course. Student can be not graded if his/her performance during semester was satisfactory but the student did not complete all obligations due to objective reasons. Such student does not have to wait next year to be graded. Many professors do not follow this distribution of marks.

Serbia is involved in European Bologna process since 2005. This means that traditional final exams at the end of semester have to be replaced with continuous work during semester. Students now have to learn during whole time of course duration while final exam is divided in several parts, but anyway it has to be noted that each year certain number of students still use to come at the end of semester and want to take classical exam.

\subsection{Pedagogical impacts of the presented spreadsheet-based problems}

High level and efficient computer software is used to help each student to simulate and solve some problems. However, such software is expensive and therefore not available for everyone. For example, MATLAB, software specialized for matrix calculation is rarely available at Serbian universities due to high costs. Spreadsheets on the other hand are almost universal on today's computers and they bridge the gap between hand calculations and high level computations. Computers are increasingly becoming available at low prices and the spreadsheet software especially. Today, use of spreadsheets is almost universal in the engineering education worldwide. Because of the mathematical nature of engineering studies the use in which spreadsheet allows for numerical computations and for creation of good charts makes it the favourite tool for engineering education.

Survey and questionnaire. Spreadsheet oriented case studies proposed in this paper were commented by students between 2006 and 2010 in Serbia. During that period students were surveyed. Questionnaire was not always identical but it was always anonymous and on voluntary base. In sum 92 students fulfilled this simple form. From the survey it can be concluded that Microsoft Excel is almost universally available (it has also to be noted that the most copies of this software in Serbia are still not legally installed). As reported by students, most of them have their own personal computer (on the other hand official statistic says that in 2010 only 35.6\% of Serbian households had personal computer and only $23.4 \%$ used internet). The surveyed students also reported that they use Serbia use wide spectrum of available software packages (in Serbia a number of them is not still legally installed). The results of the questionnaire further show that spreadsheet approach has major positive impact on the development of skills of student and that the retention of knowledge is improved compared with standard hand oriented calculations; $97 \%$ of students think that this case study spreadsheet oriented approach enable new way of thinking about the issue, $95 \%$ think that they take a more active part in the learning process, $92 \%$ think that they are more engaged in classes, $84 \%$ of students are glad because they can solve spreadsheet case study as part of exam, $68 \%$ think that they learned more in classes solving Excel exams 
(2\% think that they learned less) and 59\% think that they will more likely to do independent research outside the classroom to improve their understanding of the material ( $5 \%$ told that they do not want to do independent research). Most of students think that computer-based tools encourage spontaneous student collaboration. Some students also told on the contrary that Excel take up too much class time.

Benefits of spreadsheet oriented teaching and learning. The arguments for use of spreadsheet solver are based on the fact that basics of spreadsheets are easy to learn, the tedium of iterative calculations is easily removed letting the student to concentrate on the core of the problem, spreadsheet solver encourage structured thinking which leading to better solutions of physical problems. Most important for the students, competency in use of spreadsheets builds confidence and prepares him/her to learn higher level software and programming. This consequently means that future engineers also will be capable to solve real problems in real world and also to publish or to present orally their achievements. Solution of here presented hydraulic problem was not primarily goal. Student task will be successfully solved even if he/she e.g. try to solve very complicated network but fail. This fail attempts occurred in less than $15 \%$ of students' tasks. In such case student can pass that part of exam solving very simple network. It is important to realise that everyone learns differently. An attainable goal in some area for one student may be trivial for another. It is most relevant to develop engineering skills and creative mind than to solve each problem solely and accurately during first attempt. At the end of course most of the students are capable to solve problems in very realistic network of pipes.

Open book policy. Some lecturers, especially the older ones, sometimes use to force students to remember very complicated formulas. Time spend to memorize such materials are more or less always wasted. Today, "open book" policy can be recommended. Useful knowledge is not in memorizing of formulas but in conceptual understanding of problem. Engineering is related to the application of sciences to realworld applications, and engineering graduates must be familiar with professional problems, practical applications, and relevant solutions for the benefit of society. Engineering curricula are developed to provide students with the knowledge and skills needed to best serve their chosen industry.

External support from the experts from companies. Selected experts can be consulted to bring more realist problem to the students. In this case, attempt to involve such experts from gas distribution companies or from local municipality waterworks in teaching, failed. Surprisingly, they believe that the presented types of problems today can be solved using professional packages without going deeper into discussion about background method (goal oriented approach).

\section{Conclusion}

The reason for the wide use of spreadsheets is its design, a two-dimensional array with the capacity to link rows and columns, a classic calculation structure in engineering. A modern spreadsheet has true programming languages to carry out automation of tasks as well as powerful mathematical routines capable of solving very complex numerical problems. The use of spreadsheets is so commonplace in today's workplace that their use should be implemented in the engineering curriculum. Design project, like here presented, provide an excellent opportunity to incorporate computer usage into a 
curriculum. Furthermore, presented projects cannot be solved in easy way without the use of spreadsheet. For many students, this is the first time they have solved realistic problems. Such projects can enhance students' computer skills and prepare them for the challenges they will face on the job.

Microsoft Excel, a commonly available spreadsheet provides an efficient way to enable undergraduate students to solve a relatively complex engineering system while minimizing the computational burden (Iglesias and Paniagua 1999; Weiss and Gulliver 2001; Couvillion and Hodge 2009). Microsoft Excel can be also successfully used in other engineering fields (Brkić and Tanasković 2008).

This study examines the use of Excel, a commonly available spreadsheet package, to analyse a water distribution network. The most famous method for solving this type of problems is the Hardy-Cross method, which was firstly devised for hand calculations, in 1936 (Cross 1936). This method today has only great historical and teaching value as alma mater of all today available and more efficient methods. Example of two of these more efficient methods is shown in this paper; improved Hardy Cross method by Epp and Fowler (1970) and the node-loop method. Two presented methods are applied to develop the network equations and Excel is used to solve the nonlinear system of these equations. Convergence properties of both presented method are equally good (approximately 9 iterations are required in both presented problems). The easiness of building a new network in Excel or modifying an existing one allows the student to readily observe how small changes in the network configuration may produce interesting results such as a flow reversal in a certain conduits.

The Excel illustration is presented as a bridge that enables students to analyse more realistic applications while still requiring enough manual development to reinforce the underlying engineering principles. Computer technology plays a significant role in engineering education. Determining how and at what level to introduce technology within the curricula is a significant challenge to educators (Jewell 2001). Better students can develop some advance solutions using other software tools (Lopes 2004). Not only students of hydraulics (El-Awad 2016), but equally students with main subjects in informatics, can also participate as members of multidisciplinary students' teams. Today many studies support conclusion that the computers give unavoidable help in students' oriented teaching. Finally, everybody have to admit that such methods involved with large matrices shown in this paper cannot be used without computers, and according to teaching curriculum students have to understand essence of these methods which cannot be achieved without examples solved by students themselves.

Disclaimer. The views expressed are purely those of the writer and may not in any circumstance be regarded as stating an official position of the European Commission.

\section{References}

Aynsley, R.M. (1997). A resistance approach to analysis of natural ventilation airflow networks, J. Wind. Eng. Ind. Aerod. 67-68, 711-719. doi:10.1016/S01676105(97)00112-8 
Boulos, P.F., Lansey, K.E., and Karney, B.W. (2006). Comprehensive Water

Distribution Systems Analysis Handbook for Engineers and Planners, MWH Soft Inc, Hardback. ISBN 0-9745689-5-3

Brimberg, J., Hansen, P., Lih, K.-W., Mladenović, N., and Breton, M. (2003). An oil pipeline design problem, Oper. Res. 51 (2), 228-341.

Brkić, D. (2009). An improvement of Hardy Cross method applied on looped spatial natural gas distribution networks, Appl. Energ. 86 (7-8), 1290-1300. doi:10.1016/j.apenergy.2008.10.005

Brkić, D. (2011a). Review of explicit approximations to the Colebrook relation for flow friction, J. Petrol. Sci. Eng. 77(1), 34-48. doi:10.1016/j.petrol.2011.02.006

Brkić, D. (2011b). W solutions of the CW equation for flow friction, Appl. Math. Lett. 24(8), 1379-1383. doi:10.1016/j.aml.2011.03.014

Brkić, D. (2011c). A gas distribution network hydraulic problem from practice, Petrol. Sci. Tech. 29 (4), 366-377. doi:10.1080/10916460903394003

Brkić, D. (2011d). Iterative methods for looped network pipeline calculation, Water. Resour. Manag. 25(12), 2951-2987. doi:10.1007/s11269-011-9784-3

Brkić, D. (2012a). Determining friction factors in turbulent pipe flow, Chem. Eng. (New York) 119(3), 34-39. From: www.chemengonline.com/determiningfriction-factors-in-turbulent-pipe-flow/?printmode $=1$

Brkić, D. (2012b). Comparison of the Lambert W-function based solutions to the Colebrook equation, Eng. Computation 29(6), 617-630. doi:10.1108/02644401211246337

Brkić, D. (2017). Discussion of "Exact analytical solutions of the Colebrook-White equation" by Yozo Mikata and Walter S. Walczak, J. Hydraul. Eng. ASCE /in press/

Brkić, D., and Ćojbašić, Ž. (2016). Intelligent flow friction estimation, Comput. Intell. Neurosci. Article ID 5242596, 10 pages, doi:10.1155/2016/5242596

Brkić, D., and Tanasković, T.I. (2008). Systematic approach to natural gas usage for domestic heating in urban areas, Energy 33 (12), 1738-1753. doi:10.1016/j.energy.2008.08.009

Chansler, J.M. and Rowe, D.R. (1990). Microcomputer analysis of pipe networks, Water Eng. Manag. 137 (7), 36-39.

Ćojbašić, Ž, and Brkić, D. (2013). Very accurate explicit approximations for calculation of the Colebrook friction factor, Int. J. Mech. Sci. 67, 10-13. doi:10.1016/j.ijmecsci.2012.11.017

Colebrook, C.F. (1939). Turbulent flow in pipes with particular reference to the transition region between the smooth and rough pipe laws. J. Inst. Civil. Eng. (London) 11(4), 133-156. doi. 10.1680/ijoti.1939.13150

Colebrook, C.F., and White, C.M. (1937). Experiments with fluid friction in roughened pipes. Proc. Roy. Soc. Ser. A Math. Phys. Sci. 161(906), 367-381. doi. 10.1098/rspa.1937.0150

Corfield, G., Hunt, B.E., Ott, R.J., Binder, G.P., and Vandaveer, F.E. (1974). "Distribution design for increased demand," 63-83 [chapter 9]. In: Segeler, C.G., editor. Gas engineers handbook, Industrial Press, New York.

Couvillion, R.J., and Hodge, B.K. (2009). A unified approach to piping system problems using Excel, Comput. Educ. J., 19 (1), 24-33. 
Cross, H. (1936). Analysis of flow in networks of conduits or conductors, Urbana Champaign Univ. Ill. Bull. 286; Eng. Exp. Station, 34 (22), 3-29. https://www.ideals.illinois.edu/bitstream/handle/2142/4433/engineeringexperv 00000i00286.pdf?sequence $=3$

El-Awad, Mohamed Musaddag Dr (2016) Use of Excel's 'Goal Seek' feature for Thermal-Fluid Calculations, Spreadsheets in Education (eJSiE): Vol. 9: Iss. 1, Article 3. Available at: http://epublications.bond.edu.au/ejsie/vol9/iss1/3

Epp, R, and Fowler, A.G. (1970). Efficient code for steady flows in networks, J. Hydraul. Div. ASCE, 96 (HY1), 43-56.

Gay, B., and Middleton, P. (1971). The solution of pipe network problems, Chem. Eng. Sci., 26 (1), 109-123. doi:10.1016/0009-2509(71)86084-0

Hamam, Y.M., Brameller, A. (1971). Hybrid method for the solution of piping networks, Proc. IEE, 118 (11), 1607-1612. doi:10.1049/piee.1971.0292

Hoffmann, R., and McGuire, S.Y. (2010). Learning and teaching strategies, Am. Sci., 98 (5), 378-382. doi:10.1511/2010.86.378

Huddleston, D.H., Alarcon, V.J., and Chen, W. (2004). Water distribution network analysis using Excel. J. Hydraul. Eng. ASCE, 130 (10), 1033-1035. doi: 10.1061/(ASCE)0733-9429(2004)130:10(1033)

Iglesias, O.A., and Paniagua, C.N. (1999). Use of spreadsheets in optimization problems involving iterations, Comput. Appl. Eng. Educ., 7 (5), 227-234. doi:10.1002/(SICI)1099-0542(1999)7:4<227::AID-CAE4>3.0.CO;2-W

Jewell, T.K. (2001). Teaching hydraulic design using equation solvers, J. Hydraul. Eng. ASCE, 127 (12), 1013-1021. doi:10.1061/(ASCE)0733-9429(2001)127:12(1013)

Liou, C.P. (1998). Limitation and proper use of the Hazen-Williams equation, J. Hydraul. Div. ASCE, 124 (9), 951-954. doi:10.1061/(ASCE)07339429(1998)124:9(951)

Lopes A.M.G. (2004). Implementation of the Hardy-Cross method for the solution of piping networks, Comput. Appl. Eng. Educ., 12 (2), 117-125. doi:10.1002/cae.20006

Manojlović, V., Arsenović M. and Pajović, V. (1994). Optimized design of a gasdistribution pipeline network, Appl. Energ., 48 (3), 217-224. doi:10.1016/03062619(94)90011-6

Mikata, Y., and Walczak, W.S. (2015). Exact analytical solutions of the ColebrookWhite equation, J. Hydraul. Eng. ASCE, 04015050. doi:10.1061/(ASCE)HY.19437900.0001074

Moody L. F. (1944). Friction factors for pipe flow, Transaction of ASME, 66 (8), 671684.

Ormsbee, L.E. (2006). The history of water distribution network analysis: the computer age, 1-6. In: Buchberger, S.G., Clark, R.M., Grayman, W.M., and Uber, J.G., editors. 8th Annual Water Distribution Systems Analysis Symposium, ASCE, Cincinnati.

Pambour, K.A., Bolado, L.R., and Dijkema, G.P.J. (2016). An integrated transient model for simulating the operation of natural gas transport systems. J. Nat. Gas. Sci. Eng. 28, 672-690. doi. 10.1016/j.jngse.2015.11.036

Rollmann, P., and Spindler, K. (2015). Explicit representation of the implicit Colebrook-White equation. Case Studies in Thermal Engineering 5: 41-47. doi. 10.1016/j.csite.2014.12.001 
Shamir, U., and Howard, C.D.D. (1968). Water distribution systems analysis, J. Hydraul. Div. ASCE 94 (HY1), 219-234.

Sonnad, J.R., and Goudar, C.T. (2004). Constraints for using Lambert W functionbased explicit Colebrook-White equation. J. Hydraul. Eng. ASCE 130(9), 929931. doi. 10.1061/(ASCE)0733-9429(2004)130:9(929)

Swamee, P.K., and Rathie, P.N. (2007). Exact equations for pipe-flow problems, Journal of Hydraulic Research IAHR 45 (1), 131-134. doi:10.1080/00221686.2007.9521752

Todini, E., and Pilati, S. (1988). A gradient method for the analysis of pipe networks, 1-20. In: Coulbeck, B., and Orr, C.H., editors. Computer applications in water supply, John Wiley \& Sons Research Studies Press, London.

Travis, Q.B., and Mays, L.W. (2007). Relationship between Hazen-William and Colebrook-White roughness values, J. Hydraul. Eng. ASCE, 133 (11), 12701273. doi:10.1061/(ASCE)0733-9429(2007)133:11(1270)

Walski, T.M. (1984). Analysis of Water Distribution Systems. Van Nostrand Reinhold, New York.

Walski, T.M. (2006). Water distribution system analysis before digital computers, 1-8. In: Buchberger, S.G., Clark, R.M., Grayman, W.M., and Uber, J.G., editors. 8th Annual Water Distribution Systems Analysis Symposium, ASCE, Cincinnati.

Weiss, P.T., and Gulliver, J.S. (2001). What do students need in hydraulic design projects?, J. Hydraul. Eng. ASCE, 127 (12), 984-991. doi:10.1061/(ASCE)07339429(2001)127:12(984)

Wood, D., and Charles, C. (1972). Hydraulic network analysis using linear theory, J. Hydraul. Div. ASCE, 98 (HY7), 1157-1179.

Wood, D.J., and Rayes, A.G. (1981). Reliability of algorithms for pipe network analysis, J. Hydraul. Div. ASCE, 107 (HY10), 1145-1161. 